\title{
Cardiac medication prescribing and adherence after acute myocardial infarction in Chinese and South Asian Canadian patients
}

\author{
Emily J Lai ${ }^{*}$, Maja Grubisic ${ }^{2}$, Anita Palepu', Hude Quan ${ }^{3}$, Kathryn M King ${ }^{3}$ and Nadia A Khan
}

\begin{abstract}
Background: Failure to adhere to cardiac medications after acute myocardial infarction (AMI) is associated with increased mortality. Language barriers and preference for traditional medications may predispose certain ethnic groups at high risk for non-adherence. We compared prescribing and adherence to ACE-inhibitors (ACEI), betablockers (BB), and statins following AMI among elderly Chinese, South Asian, and Non-Asian patients.

Methods: Retrospective-cohort study of elderly AMI survivors (1995-2002) using administrative data from British Columbia. AMI cases and ethnicity were identified using validated ICD-9/10 coding and surname algorithms, respectively. Medication adherence was assessed using the 'proportion of days covered' (PDC) metric with a PDC $\geq 0.80$ indicating optimal adherence. The independent effect of ethnicity on adherence was assessed using multivariable modeling, adjusting for socio-demographic and clinical characteristics.

Results: There were 9926 elderly AMI survivors (258 Chinese, 511 South Asian patients). More Chinese patients were prescribed BBs $(79.7 \%$ vs. $73.1 \%, p=0.04)$ and more South Asian patients were prescribed statins ( $73.5 \%$ vs. $65.2 \%, p=0.001$ ). Both Chinese (Odds Ratio [OR] 0.53; 95\%Cl, 0.39-0.73; $p<0.0001$ ) and South Asian (OR 0.78; 95\% $\mathrm{Cl}, 0.61-0.99 ; \mathrm{p}=0.04)$ patients were less adherent to ACEl compared to Non-Asian patients. South Asian patients were more adherent to $\mathrm{BBs}(\mathrm{OR} 1.3 ; 95 \% \mathrm{Cl}, 1.04-1.62 ; \mathrm{p}=0.02)$. There was no difference in prescribing of $\mathrm{ACEl}$, nor adherence to statins among the ethnicities.
\end{abstract}

Conclusion: Despite a higher likelihood of being prescribed evidence-based therapies following AMl, Chinese and South Asian patients were less likely to adhere to ACEl compared to their Non-Asian counterparts.

Keywords: medication adherence, acute myocardial infarction, ethnicity

\section{Background}

Acute myocardial infarction (AMI) is one of the leading causes of death across multiple ethnic groups in North America. Landmark clinical trials established the efficacy of medications in reducing morbidity and mortality associated with AMI [1-3]. The morbidity and mortality benefits observed in these trials were largely among patients who were highly adherent. However, in real-world settings, typical adherence rates for prescribed medications are $50 \%$, and are even lower in developing countries $[4,5]$. Medication non-adherence is associated with substantial

\footnotetext{
* Correspondence: emjela@gmail.com

'Department of Medicine, University of British Columbia, 10th floor - 2775rel S Laut., Vancouver, BC V5Z 1M9, Canada

Full list of author information is available at the end of the article
}

worsening of disease, increased health care costs, and death [6-9]. From re-hospitalizations to lost workdays, the collective economic burden of non-adherence is estimated to be over $\$ 100$ billion per year.

Non-adherence is a multidimensional phenomenon, affected by socio-economic status, health systems, disease states, pharmacological therapies, and patient beliefs [5]. Whether patient ethnicity plays a role in medication adherence is unclear $[5,10]$. To date, the literature yields variable results [11-14] with little data on medication adherence in Chinese and South Asian populations, the largest, and fastest growing, ethnic groups in North America. Language barriers, mistrust of Western medicine, and preference for traditional therapies could adversely impact medication adherence in these groups.
C Biomed Central

(c) 2011 Lai et al; licensee BioMed Central Ltd. This is an Open Access article distributed under the terms of the Creative Commons Attribution License (http://creativecommons.org/licenses/by/2.0), which permits unrestricted use, distribution, and reproduction in any medium, provided the original work is properly cited. 
Furthermore, different ethnicities may react differently to the medications. For example, Asian patients have been noted to have a greater risk for adverse effects from ACEI [15]. Therefore, we compared prescribing and adherence to evidence-based therapies [ACE inhibitors (ACEI), beta-blockers (BB), and HMG-CoA reductase inhibitors (statin)] using a large multi-ethnic cohort of elderly Chinese, South Asian, and Non-Asian survivors of AMI.

\section{Methods}

Our research conformed to the Helsinki Declaration and to local legislation. Ethics approval was obtained from The University of British Columbia Providence Health Care Research Ethics Board.

\section{Data Sources}

We used hospital discharge administrative data in British Columbia (BC), Canada to identify index cases of
AMI between April $1^{\text {st }}, 1994$ and January $1^{\text {st }}, 2002$ (Figure 1). This database contains information on comorbid conditions, hospital characteristics, and demographic data. Since Canada has a universal health insurance system, this data is available for all hospitalized patients in the province.

Medication prescription (for any of ACEI, BB, or statin) was determined by linkage to the $\mathrm{BC}$ Pharmacare prescription database. These medication classes were selected because of their proven mortality benefit in secondary prevention of cardiovascular events [1-3,16-19]. The Pharmacare database contains records of all outpatient prescriptions filled in $\mathrm{BC}$ by residents aged 65 years or older including date of prescription fill and days of medication supplied. Previous studies demonstrate excellent accuracy with prescription claims databases [0.7\% error rate] [20]. By restricting our analysis to patients aged 66 years and older, we minimize the effects of patient costs on adherence as these individuals pay a deductible on medications

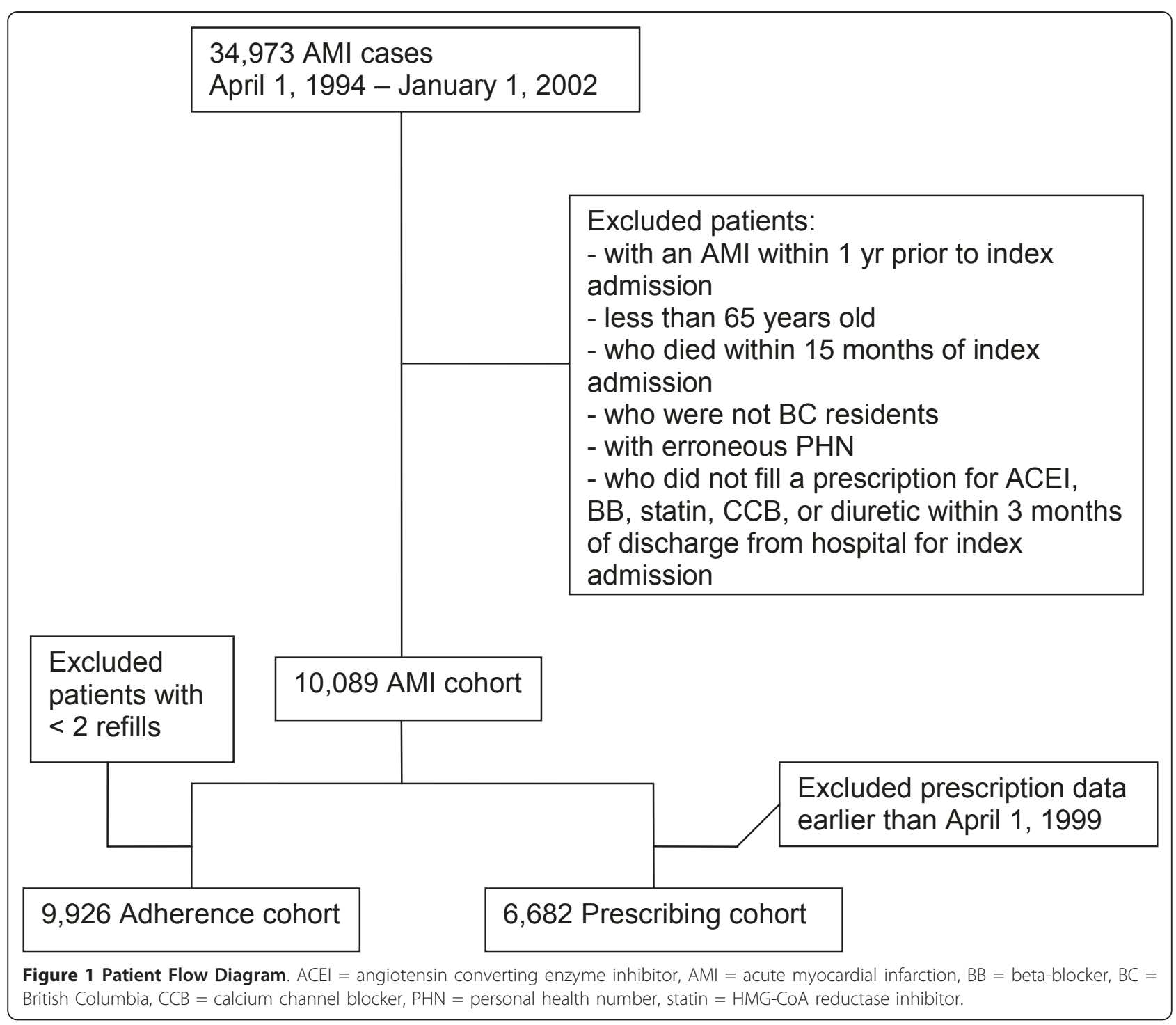


up to $\mathrm{Cdn} \$ 200 /$ year, which was increased to $\mathrm{Cdn} \$ 275 /$ year on January $1^{\text {st }}, 2002$. All medication costs above this deductible are paid by Pharmacare.

\section{Study population}

The cohort consisted of patients aged 66 years or older who were discharged from hospital with a most responsible diagnosis of AMI. To identify index AMI cases, we used the International Classification of Diseases (ICD9/ ICD10) coding algorithms for hospital administrative data [ICD9 410.x; ICD10: I21.x]. These coding algorithms for AMI have been extensively validated against multi-centre chart audits [21-23]. We only included patients who survived at least 1 year and 3 months after the hospital admission, to allow for a sufficient time period to calculate medication adherence and excluded non- $\mathrm{BC}$ residents.

\section{Identification of ethnicity}

Ethnicity is the common and/or inherited traits shared by people of the same race, ancestry, background and/or culture $[24,25]$. As self-reported ethnicity is not available in administrative databases, we used surname algorithms to categorize patient ethnicity as Chinese (from China, Taiwan or Hong Kong) or South Asian (from Pakistan, India or Bangladesh). The remaining patients will be referred to as 'Non-Asian' although 7\% of this non-Chinese, nonSouth Asian group is a visible minority according to the Canadian Census [26]. To identify patients of Chinese descent, we used Quan's surname algorithm that has a sensitivity of $78 \%$, a specificity of $99.7 \%$ and a positive predictive value of $81 \%$ compared to self-reported ethnicity using the Canadian Community Health Survey [27]. The Nam Pehchan surname algorithm has a $90-94 \%$ sensitivity, a $99.4 \%$ specificity and a positive predictive value of $63-96 \%$ for determining South Asian ethnicity $[28,29]$.

\section{Prescribing}

Since the Pharmacare database only includes data on prescription medications, we limited our selections to ACEIs, BBs, statins, calcium-channel blockers (CCB), and diuretics. Calcium-channel blockers and diuretics were included to contrast the prescribing of cardiac medications with proven and non-proven mortality benefit. Angiotensin II receptor blockers (ARBs) were not included in our analysis as these agents were not part of post-AMI guidelines during the study period. We collected data on prescribing, within the 3 months prior to AMI and at 1 year after AMI. Since prescribing patterns change over time, we restricted our collection period to April $1^{\text {st }}, 1999$ to March 31 ${ }^{\text {st }}, 2003$ to better reflect more recent prescribing practices.

\section{Assessment of adherence}

We used the 'proportion of days covered' (PDC), a commonly used metric for evaluating medication adherence.
The PDC represents the number of days a patient had a medication available, divided by the days observed $[6,30]$. Patients had to obtain a supply of medication within 3 months of hospital discharge. We used prescription data from April 1 $1^{\text {st }}, 1994$ to March $31^{\text {st }}, 2003$ to ensure we had an adequate sample size. To better reflect long-term medication adherence, we used an observation period of 1 year after the first-filled prescription [6]. A previous study of AMI patients demonstrated longer assessments of adherence were not significantly different from a oneyear measurement [6]. We calculated the PDC for a single class of medication, as well as the PDC for any one of ACEI, BB, or statin prescriptions, since our interest was in adherence to any or all proven therapies. We defined adherence as a PDC of $\geq 80 \%$, and suboptimal adherence as a PDC $<80 \%$. The $80 \%$ cut-point is similar to that used in other medication adherence studies and is associated with mortality benefit after AMI compared to other levels of adherence [6,30].

\section{Other variables}

We adjusted for several factors that have previously been shown to affect medication adherence, including previous use of the drug and number of medications (see Table 1 for list) [6,30-33]. We also adjusted for the number of hospital re-admissions within the year post-AMI as this reflects periods where patients are less likely to fill prescriptions [5,6]. To control for severity of illness on admission between ethnic groups, we used the clinical and demographic variables from the validated Ontario AMI mortality prediction rule [34].

\section{Statistical analysis}

Baseline characteristics were compared between ethnic groups using chi-square testing for categorical variables and ANOVA for continuous variables. Missing values, found in measures of socio-economic status quintile (< $4.8 \%$ ), were excluded from the analysis (see Table 1). Multivariable logistic regression models, adjusting for age, sex, residential distance from hospital, income quintile, admission year, number of baseline medications, number of readmissions to hospital, prior use of same medication, and comorbid conditions from the Ontario AMI prediction rule, were constructed to examine the independent relationship between adherence (PDC $\geq 80 \%$ ) and ethnicity. Logistic regression model assumptions were satisfied. Statistical significance was defined as a 2-tailed $p<0.05$. All analyses were performed using SAS statistical software version 9.1 (SAS Institute Inc, Cary, NC).

\section{Results}

\section{Baseline characteristics}

Of 9926 patients who met inclusion criteria, 258 (2.6\%) were Chinese, 511 (5.1\%) were South Asian, and 9157 
Table 1 Patient characteristics according to ethnicity

\begin{tabular}{|c|c|c|c|c|}
\hline Characteristic & Chinese & South Asian & Non-Asian & p-value \\
\hline & $N=258$ & $N=511$ & $N=9157$ & \\
\hline \multicolumn{5}{|l|}{ Age, n (\%) } \\
\hline 65-69 years & $66(25.6)$ & $167(32.7)$ & $2297(25.1)$ & 0.0006 \\
\hline $70-74$ years & $63(24.4)$ & $143(28)$ & $2330(25.5)$ & 0.40 \\
\hline $75-79$ years & $62(24)$ & $104(20.4)$ & $2111(23.1)$ & 0.34 \\
\hline$\geq 80$ years & $67(26)$ & $97(19)$ & $2419(26.4)$ & 0.001 \\
\hline Female, n (\%) & $93(36.1)$ & $204(39.9)$ & $3718(40.6)$ & 0.33 \\
\hline \multicolumn{5}{|l|}{ Income, n (\%) * } \\
\hline$<\$ 30,569$ & $83(32.2)$ & $129(25.2)$ & 2165 (23.6) & $<0.0001$ \\
\hline$\$ 30,570-43,147$ & $78(30.2)$ & $138(27)$ & $1735(19)$ & $<0.0001$ \\
\hline$\$ 43,148-54,103$ & $36(14)$ & $110(21.5)$ & $1642(17.9)$ & $<0.0001$ \\
\hline$\$ 54,104-68,206$ & $23(8.9)$ & $62(12.1)$ & 1609 (17.6) & $<0.0001$ \\
\hline$\$ 68,207-221,991$ & $35(13.6)$ & $55(10.8)$ & $1559(17)$ & $<0.0001$ \\
\hline$>50 \mathrm{~km}$ to hospital, n (\%) & $12(4.7)$ & $74(14.5)$ & $3181(34.7)$ & $<0.0001$ \\
\hline Number of hospitalizations, mean (SD) & $0.18(0.49)$ & $0.31(0.66)$ & $0.3(0.64)$ & $<0.0001$ \\
\hline Total \# of medications ${ }^{\dagger}$, mean (SD) & $7.51(3.81)$ & $8.18(3.9)$ & $7.32(3.63)$ & 0.011 \\
\hline Prior use of $\mathrm{ACEl}, \mathrm{BB}$, or statin ${ }^{\ddagger}, \mathrm{n}(\%)$ & $109(42.3)$ & $188(36.8)$ & $3376(36.9)$ & 0.21 \\
\hline \multicolumn{5}{|l|}{ Comorbidities, n (\%) } \\
\hline Diabetes & $67(26)$ & $152(29.8)$ & $1526(16.7)$ & $<0.0001$ \\
\hline $\mathrm{CHF}$ & $58(22.5)$ & $110(21.5)$ & $1570(17.2)$ & 0.004 \\
\hline Cardiac & $40(15.5)$ & $60(11.7)$ & $1392(15.2)$ & 0.10 \\
\hline PAD & $7(2.7)$ & $4(0.8)$ & $342(3.7)$ & 0.0016 \\
\hline Hypertension & $98(38)$ & $160(31.3)$ & $2402(26.2)$ & $<0.0001$ \\
\hline Cerebrovascular & $12(4.7)$ & $9(1.8)$ & $203(2.2)$ & 0.03 \\
\hline Kidney disease & $15(5.8)$ & $16(3.1)$ & $180(2)$ & $<0.0001$ \\
\hline
\end{tabular}

Abbreviations: $\mathrm{ACEI}=$ angiotensin-converting-enzyme inhibitor; $\mathrm{BB}=$ beta-blocker; $\mathrm{CHF}=$ congestive heart failure; $\mathrm{PAD}=$ peripheral arterial disease; $\mathrm{PDC}=$ proportion of days covered.

* Missing socio-economic status data was < 4.8\% (1.6\% Chinese, 3.4\% South Asians, 4.9\% Non-Asians).

${ }^{+}$Within 3 months of discharge from index admission date.

₹ Within 3 months prior to index admission date.

(92.3\%) were categorized as Non-Asian. Table 1 illustrates baseline socio-demographic and clinical characteristics between the three ethnic groups. Chinese and South Asian patients tended to reside in urban areas and comprised a larger proportion of the lower income quintiles than Non-Asian patients. There were more Chinese and South Asian patients with diabetes, congestive heart failure, kidney disease, hypertension, and more Chinese patients with cerebrovascular disease. Both Chinese and South Asian patients were prescribed a greater number of total medications within 3 months of hospital discharge.

\section{Prescribing of evidence-based therapies}

In all ethnic groups, there were significant increases in prescriptions for evidence-based therapies after discharge from hospital for AMI (Table 2). However, despite the high risk of re-infarction, $25 \%$ of patients did not fill a prescription for any evidence-based therapies. Compared to Non-Asian patients, Chinese patients were more likely prescribed BBs, while South Asian patients were more likely prescribed statins. There was no significant difference in ACEI prescribing between the ethnic groups. There was also no difference in prescribing of CCBs between the ethnic groups. While more NonAsian patients were prescribed diuretics prior to AMI, there was no difference in diuretic prescriptions between the ethnic groups post-AMI.

\section{Adherence to evidence-based therapies}

The majority (79.9\%) of patients were adherent to at least one of the three evidence-based therapies (Table 3). In the unadjusted analysis, there was no significant difference between the ethnic groups for adherence to any one of ACEI, BB, or statin medication (82.6\% South Asian vs. 76.4\% Chinese vs. 79.9\% Non-Asian patients). Examining 
Table 2 Medication prescribing according to ethnicity 3 months prior to AMI and 1 year post AMI, n (\%)

\begin{tabular}{|c|c|c|c|c|c|c|c|c|}
\hline \multirow[t]{2}{*}{ Medication } & \multicolumn{4}{|c|}{3 months prior to AMI } & \multicolumn{4}{|c|}{1 year post AMI } \\
\hline & $\begin{array}{l}\text { Chinese } \\
(n=150)\end{array}$ & $\begin{array}{l}\text { South Asian } \\
(n=224)\end{array}$ & $\begin{array}{l}\text { Non-Asian } \\
(\mathrm{n}=3697)\end{array}$ & p-value & $\begin{array}{l}\text { Chinese } \\
(n=197)\end{array}$ & $\begin{array}{l}\text { South Asian } \\
(\mathrm{n}=370)\end{array}$ & $\begin{array}{l}\text { Non-Asian } \\
(\mathrm{n}=6115)\end{array}$ & $\mathrm{p}$-value \\
\hline ACEI & $66(44)$ & $86(38.4)$ & $1586(42.9)$ & 0.39 & $157(79.7)$ & $293(79.2)$ & $4621(75.6)$ & 0.13 \\
\hline$\overline{\mathrm{BB}}$ & $56(37.3)$ & $66(29.5)$ & $1134(30.7)$ & 0.2 & $157(79.7)$ & $286(77.3)$ & $4472(73.1)$ & $0.03^{*}$ \\
\hline Statin & $40(26.7)$ & 69 (30.8) & $973(26.3)$ & 0.34 & $132(67)$ & $272(73.5)$ & 3987 (65.2) & $0.004^{\dagger}$ \\
\hline ACEI, BB, or Statin & $110(73.3)$ & $154(68.8)$ & $2641(71.4)$ & 0.59 & $194(98.5)$ & $360(97.3)$ & $5867(95.9)$ & 0.09 \\
\hline$\overline{C C B}$ & $61(40.7)$ & $84(37.5)$ & $1312(35.5)$ & 0.37 & $66(33.5)$ & $131(35.4)$ & $1856(30.4)$ & 0.09 \\
\hline Diuretic & $42(28)$ & 76 (33.9) & $1568(42.4)$ & $<0.001$ & $104(52.8)$ & $189(51.2)$ & $2990(48.9)$ & 0.42 \\
\hline
\end{tabular}

Abbreviations: $\mathrm{ACEI}=$ angiotensin-converting-enzyme inhibitor; $\mathrm{AMI}=$ acute myocardial infarction; $\mathrm{BB}=$ beta-blocker; $\mathrm{CCB}=$ calcium-channel blocker.

* For BBs: Chinese vs. Non-Asian, $p=0.04$; South Asian vs. Non-Asian, $p=0.08$.

${ }^{+}$For statins: Chinese vs. Non-Asian, $p=0.6$; South Asian vs. Non-Asian, $p=0.001$.

individual classes of medications, there was a smaller proportion of Chinese patients adhering to ACEI and a larger proportion of South Asian patients adhering to BBs relative to Non-Asian patients. Adherence to statins was similar across all ethnic groups. Adherence to CCBs and diuretics was also similar across all ethnicities, although adherence rates for diuretics were low in all groups.

In the adjusted analysis, Chinese patients were less likely to adhere to ACEI, compared to Non-Asians, [OR 0.53; 95\%CI: 0.39-0.73]. Chinese patients, overall, were also less likely to be adherent to any of ACEI, BB, or statin medication [OR 0.70; 95\%CI: 0.51-0.95]. Compared to Non-Asians, South Asians were less likely to be adherent to ACEI [OR 0.78; 95\%CI: 0.61-0.99] but more likely to be adherent to BBs [OR 1.3; 95\%CI: 1.04-1.62]. Among the medications with less evidence for cardioprotection, there was no significant difference in adherence to CCBs, but South Asian patients were less likely to adhere to diuretics compared to Non-Asian patients.

\section{Discussion}

In this study, elderly Chinese and South Asian patients were as or more likely to be prescribed evidence-based therapies following AMI compared to their Non-Asian counterparts. However, adherence varied by medication class in the ethnic groups.

Overall prescribing rates for secondary prevention of AMI were poor for statin medications (68\%) but higher for ACEI and BB medications (77-78\%). Overall prescribing of these medications was similar to those in other studies $[6,35]$. Appropriately, we saw a decrease in prescribing for CCBs. We found that Chinese and South Asian patients were more likely to be prescribed BBs and statins compared to Non-Asian patients. Reasons for this are unclear; prescribing physicians may consider Chinese and South Asian patients to be at higher cardiac risk, necessitating more aggressive management. Studies demonstrate that South Asian patients, for example, are more or just as likely to receive invasive cardiovascular procedures following AMI, compared to their Non-Asian counterparts [36]. Alternatively, Chinese and South Asian patients may have been more likely to fill their prescriptions once discharged from hospital compared to Non-Asian patients. Non-Asian patients tended to reside outside of urban areas where access to medical follow-up was perhaps more limited, potentially resulting in fewer opportunities to fill prescriptions.

This study found that elderly Chinese patients were less likely to adhere to any evidence based therapy following

Table 3 Adherence to cardiac medications (PDC $\geq 80 \%$ ) according to ethnicity and medication

\begin{tabular}{|c|c|c|c|c|c|c|c|c|}
\hline \multirow[t]{2}{*}{ Medication } & \multirow[t]{2}{*}{ Chinese } & \multirow[t]{2}{*}{ South Asian } & \multirow[t]{2}{*}{ Non-Asian } & \multirow[t]{2}{*}{$p$-value } & \multicolumn{2}{|c|}{ Adj. OR $(95 \% \mathrm{Cl})^{*}$} & \multicolumn{2}{|l|}{ Adj. OR $(95 \% \mathrm{Cl})^{*}$} \\
\hline & & & & & Chinese vs. Non-Asian & p-value & South Asian vs. Non-Asian & p-value \\
\hline ACEl, \% & 63.5 & 71.4 & 75 & $<0.001$ & $0.53(0.39-0.73)$ & $<0.001$ & $0.78(0.61-0.99)$ & 0.04 \\
\hline $\mathrm{BB}, \%$ & 54.1 & 63.4 & 56.4 & 0.02 & $0.85(0.63-1.15)$ & 0.29 & $1.3(1.04-1.62)$ & 0.02 \\
\hline Statin, \% & 80.8 & 85.4 & 81 & 0.19 & $0.83(0.52-1.35)$ & 0.46 & $1.26(0.88-1.79)$ & 0.21 \\
\hline $\mathrm{CCB}, \%$ & 64 & 68.4 & 65.5 & 0.73 & $0.84(0.51-1.38)$ & 0.49 & $1.07(0.74-1.53)$ & 0.73 \\
\hline Diuretic, \% & 35.9 & 33.8 & 39.5 & 0.18 & $0.84(0.55-1.28)$ & 0.41 & $0.73(0.54-0.99)$ & 0.04 \\
\hline ACEI, BB, or statin, $\%$ & 76.4 & 82.6 & 79.9 & 0.12 & $0.70(0.51-0.95)$ & 0.02 & $1.01(0.79-1.29)$ & 0.92 \\
\hline
\end{tabular}

Abbreviations: $\mathrm{ACEI}=$ angiotensin-converting-enzyme inhibitor; $\mathrm{Adj}$. OR = adjusted odds ratio; $\mathrm{BB}=$ beta-blocker; $\mathrm{CCB}=$ calcium-channel blocker; $\mathrm{PDC}=$ proportion of days covered

* odds ratios adjusted for age, gender, residential distance from hospital, socio-economic status, admission year, number of baseline medications, number of re-admissions to hospital, prior use of same medication, and comorbidities 
AMI relative to Non-Asian patients. To our knowledge, this is the first study evaluating the adherence to secondary prevention medications following AMI in Chinese and South Asian patients. In addition to the factors associated with non-adherence found in the general population, non-adherence in these ethnic populations may be further amplified by language barriers [37-40] and differences in health literacy [40-42] among ethnocultural groups. Furthermore, ethnocultural patients may have a preference for alternative or natural therapies [43-45], and some may perceive that antihypertensive therapy is not beneficial [46]. Furthermore, differences in health beliefs and strong Eastern views of care (e.g. viewing disease as a result of fate and avoidance of medical visits) are associated with poor adherence to treatment recommendations [47]. Intriguingly, even within the same class of medication, we found that adherence varied by patient ethnicity with the greatest proportion of suboptimal adherence for ACEI in both Chinese and South Asian patients. This observation raises suspicion that the differences in adherence may be, at least in part, attributed to greater adverse effect profiles within these ethnic groups. In a systematic review of cardiovascular drug utilization, ACEI-induced cough was more prevalent in Asian patients than in the general population, although South Asian patients were not studied separately [15]. Adherence to statins was similar across ethnic groups despite the fact that, in post-marketing surveillance, rosuvastatin was associated with greater statin-induced myopathy in Asian patients [48].

This study had several limitations. First, we only used a proxy measurement for adherence using prescriptions claims data. Although this approach does not ensure that the medications were ingested, prescription claims data highly correlates with home inventory pill counts, as well as serum measures of drug presence [49-51]. As with all observational studies, we were limited by residual confounders since we were unable to assess other factors associated with non-adherence such as dementia and depression. Similarly, we did not have access to other clinical information such as left ventricular function or creatinine, but we attempted to adjust for some of the clinical variables by including the diagnosis of CHF or kidney disease, for example, in Table 1. We did not include Angiotensin receptor blockers (ARBs) in our analysis. These agents have become more widely used since the study period, and are often prescribed for patients who experience negative side effects from ACEI, thereby potentially impacting adherence to any renin-angiotensin-aldosterone agent (either ACEI or ARBs). Finally, we investigated medication adherence among major ethnic groups in Canada who were elderly; these results may not be generalized to other ethnic groups or to younger patients within these groups.

\section{Conclusions}

Compared to their Non-Asian counterparts, South Asian and Chinese elderly patients are just as likely or more likely to receive proven secondary prevention therapies. However, in this cohort of high cardiac risk patients, 25\% of patients did not fill a prescription for these therapies, suggesting greater need to improve prescribing in all ethnic groups following AMI. Chinese patients were less likely to be adherent to any secondary prevention medication and specifically, ACEI therapy. South Asian patients were also less likely to be adherent to ACEI therapy relative to their Non-Asian counterparts. This study identifies an at-risk group of patients that require aggressive monitoring, follow-up and support to optimize adherence. Future studies evaluating underlying cultural barriers to adherence are needed to develop culturally-tailored interventions to improve adherence. The disproportionately lower adherence to ACEI in South Asian and Chinese patients, raises suspicion that both of these groups may suffer greater adverse effects associated with ACEI.

\section{Acknowledgements}

The Canadian Institutes of Health Research provided funding for the study. Salary support for the co-authors was provided by the Canadian Institutes of Health Research (HQ, AP, NAK), Michael Smith Foundation for Health Research (AP), and Alberta Heritage Foundation for Medical Research (HQ, KMK). NAK and MG had full access to all of the data in the study and take responsibility for the integrity of the data and the accuracy of the data analysis.

\section{Author details}

'Department of Medicine, University of British Columbia, 10th floor - 2775rel S Laut., Vancouver, BC V5Z 1M9, Canada. ${ }^{2}$ Center for Health Evaluation and Outcomes Sciences, St. Paul's Hospital, 620B - 1081 Burrard St., Vancouver, BC V6Z 1Y6, Canada. ${ }^{3}$ Department of Community Health Sciences, University of Calgary, TRW Bldg 3rd floor - 3280 Hospital Dr NW, Calgary, AB T2N 4Z6, Canada.

\section{Authors' contributions}

All authors listed have contributed sufficiently to the project to be included as authors. All authors contributed to the acquisition and analysis/ interpretation of data, as well as revised the manuscript. In addition, EJL drafted the manuscript and NAK contributed to the conception and design. All authors have given final approval of the version to be published.

\section{Competing interests}

The authors declare that they have no competing interests.

Received: 28 January 2011 Accepted: 18 September 2011 Published: 18 September 2011

\section{References}

1. First International Study of Infarct Survival collaborative group: Randomized trial of intravenous atenolol among 16,027 cases of suspected acute myocardial infarction: ISIS-1. Lancet 1986, 2:57-66.

2. Heart Outcomes Prevention Evaluation Study Investigators: Effects of an angiotensin-converting-enzyme inhibitor, ramipril, on cardiovascular events in high-risk patients. N Engl J Med 2000, 342:145-53.

3. Heart Protection Study Collaborative Group: MRC/BHF Heart Protection Study of cholesterol lowering with simvastatin in 20536 high-risk individuals: a randomized placebo-controlled trial. Lancet 2002, 360:7-22.

4. Sackett $\mathrm{DL}$, Snow JC: The magnitude of adherence and nonadherence. In Compliance in Health Care. Edited by: Haynes RB, Taylor DW, Sackett DL. Baltimore: Johns Hopkins University Press; 1979:11-22. 
5. Sabate E: Adherence to long-term therapies: evidence for action Geneva: World Health Organization; 2003.

6. Rasmussen JN, Chong A, Alter DA: Relationship between adherence to evidence-based pharmacotherapy and long-term mortality after acute myocardial infarction. JAMA 2007, 297:177-86.

7. Berg JS, Dischler J, Wagner DJ, Raia JJ, Palmer-Shevlin N: Medication compliance: a healthcare problem. Ann Pharmacother 1993, 27(suppl 9): S1-24.

8. Rodgers PT, Ruffin DM: Medication nonadherence - Part I: The health and humanistic consequences. Manag Care Interface 1998, 11:58-60.

9. Rodgers PT, Ruffin DM: Medication nonadherence - Part II: a pilot study in patients with congestive heart failure. Manag Care Interface 1998, 11:67-9, 75.

10. Osterberg L, Blaschke T: Adherence to medication. N Engl J Med 2005, 353:487-97.

11. Francis CK: Hypertension, cardiac disease, and compliance in minority patients. Am J Med 1991, 91:1A.29S-365.

12. Charles $\mathrm{H}$, Good C, Hanusa BH, Chang CH, Whittle J: Racial differences in adherence to cardiac medications. J Natl Med Assoc 2003, 95:17-22.

13. Bosworth HB, Dudley T, Olsen MK, Voils Cl, Powers B, Goldstein MK, Oddone EZ: Racial differences in blood pressure control: potential explanatory factors. Am J Med 2006, 119:70.e9-15.

14. Siegel $\mathrm{D}$, Lopez J, Meier J: Antihypertensive medication adherence in the Department of Veterans Affairs. Am J Med 2007, 120:26-32.

15. McDowell SE, Coleman JJ, Ferner RE: Systematic review and meta-analysis of ethnic differences in risks of adverse reactions to drugs used in cardiovascular medicine. BMJ 2006, 332:1177-81.

16. Freemantle N, Cleland J, Young P, Mason J, Harrison J: $\beta$ blockade after myocardial infarction: systematic review and meta regression analysis. BMJ 1999, 318:1730-7.

17. The Scandinavian Simvastatin Survival Study group: Randomized trial of cholesterol lowering in $\mathbf{4 4 4 4}$ patients with coronary heart disease: the Scandinavian simvastatin survival study (4S). Lancet 1994, 344:1383-9.

18. Ryan TJ, Antman EL, Brooks NH, Califf RM, Hillis LD, Hiratzka LF, Rapaport E, Reigel BJ, Russell RO, Smith III EE, Weaver WD: 1999 update: ACC/AHA guidelines for the management of patients with acute myocardial infarction: a report of the American College of Cardiology/American Heart Association Task Force on Practice Guidelines (Committee on Management of Acute Myocardial Infarction). J Am Coll Cardiol 1999, 34:890-911.

19. Braunwald E, Antman EL, Beasley JW, Califf RM, Cheitlin MD, Hochman JS, Jones RH, Kereiakes D, Kupersmith J, Levin TN, Pepine CJ, Schaeffer JW, Smith III EE, Steward DE, Theroux P: ACC/AHA guideline update for the management of patients with unstable angina and non-ST-segment elevation myocardial infarction: a report of the American College of Cardiology/American Heart Association Task Force on Practice Guidelines (Committee on the Management of Patients with Unstable Angina). J Am Coll Cardiol 2002, 40:1366-74.

20. Levy AR, O'Brien BJ, Sellors C, Grootendorst P, Willison D: Coding accuracy of administrative drug claims in the Ontario Drug Benefit database. Can J Clin Pharmacol 2003, 10:67-71.

21. Quan J, Parson G, Ghali W: Validity of information on comorbidity derived from ICD-9-CM administrative data. Medical care 2002, 40:675-85.

22. Tu JV, Austin $\mathrm{PC}$, Naylor $\mathrm{CD}$, Iron $\mathrm{K}$, Zhang $\mathrm{H}$ : Acute myocardial infarction outcomes in Ontario. In Cardiovascular health and services in Ontario: An ICES atlas. Edited by: Naylor CD, Slaughter PM. Toronto, Ontario: Institute for Clinical Evaluative Sciences; 1999:83-110

23. Vermeulen MJ, Tu JV, Schull MJ: ICD-10 adaptations of the Ontario acute myocardial infarction mortality prediction rules performed as well as the original versions. J Clin Epidemiol 2007, 60:971-4

24. Masi R: Multiculturalism, medicine and health Part I: Multicultural health care. Can Fam Physician 1988, 2173-2178.

25. Waxler-Morrison N, Anderson J, Richardson E: Cross-cultural caring. A handbook for health professionals in Western Canada Vancouver, BC: University of British Columbia Press; 1990.

26. Statistics Canada 2001 Census of Canada. [http://www12.statcan.ca/ english/census01/products/analytic/companion/etoimm/canada. cfm\#threefold_increase].

27. Quan H, Wang F, Schopflocher D, Norris C, Galbraith PD, Faris $P$, Graham MM, Knudtson ML, Ghali WA: Development and validation of a surname list to define Chinese ethnicity. Medical Care 2006, 44:328-33.
28. Harding S, Dew H, Simpson SL: The potential to identify South Asians using a computerized algorithm to classify names. Popul Trends 1999, 97:46-9.

29. Cummins C, Winter H, Cheng KK, Maric R, Silcocks P, Varghese C: An assessment of the Nam Pehchan computer program for the identification of names of south Asian ethnic origin. J Public Health Med 1999, 21:401-6

30. Benner JS, Glynn RJ, Mogun H, Neumann PJ, Weinstein MC, Avorn J: Longterm persistence in use of statin therapy in elderly patients. JAMA 2002, 288:455-61.

31. Balkrishnan R: Predictors of medication adherence in the elderly. Clin Ther 1998, 20:764-71.

32. Ammassari A, Trotta MP, Murri R, Castelli F, Narciso P, Noto P, Vecchiet J, Monforte A, Wu AW, Antinori A: Correlates and predictors of adherence to highly active antiretroviral therapy: overview of published literature. J Acquir Immune Defic Syndr 2002, 31(suppl 3):S123-7.

33. Schroeder K, Fahey T, Ebrahim S: Interventions for improving adherence to treatment in patients with high blood pressure in ambulatory settings. Cochrane Database of systematic reviews 2004, , 3: CD004804.

34. Tu JV, Austin PC, Walld R, Roos L, Agras J, McDonald KM: Development and validation of the Ontario acute myocardial infarction mortality prediction rules. J Am Coll Cardiol 2001, 37:992-7.

35. Gislason GH, Rasmussen JN, Abildstrom SZ, Gadsboll N, Buch P, Friberg J, Rasmussen S, Kober L, Stender S, Madsen M, Torp-Pedersen C: Long-term compliance with beta-blockers, angiotensin-converting enzyme inhibitors, and statins after acute myocardial infarction. Eur Heart J 2006, 27:1153-8

36. Britton A, Shipley M, Marmot M, Hemingway H: Does access to cardiac investigation and treatment contribute to social and ethnic differences in coronary heart disease? Whitehall II prospective cohort study. BM」 2004, 329:318-23.

37. Lopez-Quintero C, Berry EM, Neumark Y: Limited English proficiency is a barrier to receipt of advice about physical activity and diet among Hispanics with chronic diseases in the United States. J Am Diet Assoc 2009, 109:1769-74

38. King KM, LeBlanc P, Sanguins J, Mather C: Gender-based challenges faced by older Sikh women as immigrants: recognizing and acting on the risk of coronary artery disease. Can J Nurs Res 2006, 38:16-40.

39. King KM, LeBlanc P, Carr W, Quan H: Chinese immigrants' management of their cardiovascular disease risk. West J Nurs Res 2007, 29:804-26.

40. King KM, Mather CD, Sanguins J: Ethnocultural affiliation, gender, and cardiovascular disease risk management. Can J Cardiovasc Nurs 2005, 15:10-6.

41. Washington G, Wang-Letzkus MF: Self-care practices, health beliefs, and attitudes of older diabetic Chinese Americans. J Health Hum Serv Adm 2009, 32:305-23.

42. Lindesay J, Jagger C, Hibbett MJ, Peet SM, Moledina F: Knowledge, uptake and availability of health and social services among Asian Gujarati and white elderly persons. Ethn Health 1997, 2:59-69.

43. Pieroni A, Sheikh QZ, Ali W, Torry B: Traditional medicines used by Pakistani migrants from Mirpur living in Bradford, Northern England. Complement Ther Med 2008, 16:81-6.

44. Odegard PS, Gray SL: Barriers to medication adherence in poorly controlled diabetes mellitus. Diabetes Educ 2008, 34:692-7.

45. Krousel-Wood MA, Muntner P, Joyce CJ, Islam T, Stanley E, Holt EW, Morisky DE, He J, Webber LS: Adverse effects of complementary and alternative medicine on antihypertensive medication adherence: findings from the cohort study of medication adherence among older adults. J Am Geriatr Soc 2010, 58:54-61.

46. Li WW, Froelicher ES: Gender differences in Chinese immigrants: predictors for antihypertensive medication adherence. $J$ Transcult Nurs 2007, 18:331-8.

47. Li WW, Stotts NA, Froelicher ES: Compliance with antihypertensive medication in Chinese immigrants: cultural specific issues and theoretical application. Res Theory Nurs Pract 2007, 21:236-54.

48. Health Canada safety information for rosuvastatin (Crestor). [http://www. hc-sc.gc.ca/ahc-asc/media/advisories-avis/_2005/2005_10-eng.php].

49. Lau HS, de Boer A, Beuning KS, Porsius A: Validation of pharmacy records in drug exposure assessment. J Clin Epidemiol 1997, 50:619-625.

50. Steiner JF, Prochazka AV: The assessment of refill compliance using pharmacy records: methods, validity, and applications. J Clin Epidemiol 1997, 50:105-16 
51. West SL, Savitz DA, Koch G, Strom BL, Guess HA, Hartzema A: Recall accuracy for prescription medications: self-report compared with database information. Am J Epidemiol 1995, 142:1104-12.

\section{Pre-publication history}

The pre-publication history for this paper can be accessed here: http://www.biomedcentral.com/1471-2261/11/56/prepub

doi:10.1186/1471-2261-11-56

Cite this article as: Lai et al:: Cardiac medication prescribing and

adherence after acute myocardial infarction in Chinese and South Asian Canadian patients. BMC Cardiovascular Disorders 2011 11:56.

Submit your next manuscript to BioMed Central and take full advantage of:

- Convenient online submission

- Thorough peer review

- No space constraints or color figure charges

- Immediate publication on acceptance

- Inclusion in PubMed, CAS, Scopus and Google Scholar

- Research which is freely available for redistribution 